F. Child Lang. 32 (2005), 855-876. (C) 2005 Cambridge University Press doi:I0.1017/So30500090500705 I Printed in the United Kingdom

\title{
Lexical and referential cues to sentence interpretation: an investigation of children's interpretations of ambiguous sentences*
}

\author{
EVAN KIDD \\ Max Planck Child Study Centre, University of Manchester \\ AND \\ EDITH L. BAVIN \\ La Trobe University \\ (Received 4 May 2004. Revised 2 I February 2005)
}

\begin{abstract}
This paper reports on an investigation of children's (aged $3 ; 5^{-9} ; 8$ ) comprehension of sentences containing ambiguity of prepositional phrase (PP) attachment. Results from a picture selection study $(N=90)$ showed that children use verb semantics and preposition type to resolve the ambiguity, with older children also showing sensitivity to the definiteness of the object NP as a cue to interpretation. Study 2 investigated three- and five-year-old children's $(N=47)$ ability to override an instrumental interpretation of ambiguous PPs in order to process attributes of the referential scene. The results showed that while five-year-olds are capable of incorporating aspects of the referential scene into their interpretations, three-year-olds are not as successful. Overall, the results suggest that children are attuned very early to the lexico-semantic co-occurrences that have been shown to aid ambiguity resolution in adults, but that more diffuse cues to interpretation are used only later in development.
\end{abstract}

[*] This research was supported by an Australian Postgraduate Award to the first author while a PhD student at La Trobe University, and a postdoctoral fellowship to the first author from the Max Planck Institute for Evolutionary Anthropology, Leipzig. We would like to thank Rosy Colville for help in testing for Study 2 and Keith Brown for doing the drawings for Study I. Thanks also to Jesse Snedeker for helpful comments on the thesis on which some of this paper is based. Address for correspondence: Evan Kidd, School of Psychological Sciences, University of Manchester, Oxford Rd, Manchester Mi3 9PL, UK. tel: +44 I6r 275 2594; fax: +44 I6r 275 8587; e-mail: evan.j.kidd@ manchester.ac.uk 
INTRODUCTION

Bever (I970) suggested that the functional process of language use drives acquisition. More recently Fodor (I998) argued that, logically, children must be able to process language input in order to learn it. Certainly infants must be able to segment the input in order to determine the categories of their language, and there is now a body of research on infants' early segmentation. In particular, Jusczyk's research findings (e.g. I997, 2002) show evidence that infants become familiar with recurring patterns in the input language. Other researchers have demonstrated how distributional patterns could be detected in the input (e.g. Mintz, Newport \& Bever, 2002), and still others have investigated how children process language at the sentential level (e.g. MacWhinney \& Bates, r 989; Frazier \& de Villiers, I 990; Booth, MacWhinney \& Harasaki, 2000).

Bates \& MacWhinney's ( I 989) COMPETITION MODEL suggests that children interpret language using cues of varying strength, which in turn vary across languages. For instance, word order is a reliable cue to agency in English, whereas semantics (animacy) is a more reliable cue in Italian. These cues enable children to decipher 'who is doing what to whom'. The construct of CUE RELIABILITY is well attested in studies conducted in a number of different languages (see MacWhinney \& Bates, I989). In contrast to this rich literature, little is known about how children interpret ambiguous sentences, where a scene can be correctly interpreted in more than one way. The present paper considers the lexical and referential cues that children use to resolve sentences containing ambiguity of prepositional phrase (PP) attachment.

\section{Prepositional Phrase attachment}

Hindle \& Rooth (I993) suggest that PP attachment ambiguity is the canonical form of syntactic ambiguity. Consider sentence (I).

(I) The woman waved to the man with the flag

In (I) the ambiguous PP with the flag can attach either to the verb waved or the object NP the man. When the PP with the flag attaches to the verb (VP-attachment), the sentence can be paraphrased as 'The woman waved the flag to the man'. When the PP attaches to the object NP (NP-attachment), the sentence can be paraphrased as 'The woman waved to the man who has the flag'; the PP serves to identify the man as a unique referent.

Preposition phrase attachment has been the focus of a number of studies of adult sentence processing (e.g. Ferreira \& Clifton, i986, Taraban \& McClelland, I988, I990; Spivey-Knowlton \& Sedivy, I995). The predominant structural model of processing, the Garden-Path model (Frazier, I987), predicts that the ambiguous PP is attached to the verb

$$
856
$$


before any potentially disambiguating non-structural information is considered, via the processing heuristic Minimal Attachment (MA). While there is a body of evidence supporting MA by adults (e.g. Rayner, Carlson \& Frazier, I983; Ferreira \& Clifton, I986; Clifton \& Ferreira, I989), some researchers have argued that initial interpretations can be influenced by non-structural factors.

For example, Taraban \& McClelland (I988, I990) proposed that the semantic content of each constituent in a verb-object-PP (V-NP-PP) sequence produces an expectation that favours either VP- or NP-attachment of the PP. In (2a) the PP is VP-attached, yielding the interpretation that every painting was stolen in a discrete time period (the night). In (2b), however, the PP is NP-attached, with the interpretation that only those paintings contained in the museum were stolen. The sentences differ only in the sentence final NP. Taraban \& McClelland argue that the semantic role of each constituent is evaluated with reference to its role in the event being described, such that initial attachment preference is the outcome of a confluence of cues.

(2a) The thieves stole all the paintings in the night.

(2b) The thieves stole all the paintings in the museum.

Spivey-Knowlton \& Sedivy (I995) have shown that both verb semantics and definiteness of the object NP in a V-NP-PP sequence affect PPattachment. Their experiments with adults suggested that ambiguous $\mathrm{V}-\mathrm{NP}-\mathrm{PP}$ sequences are more likely to have a VP-attachment interpretation if the sequence contains an action verb. Conversely, PPs in an ambiguous sequence with a verb of perception or a psychological predicate are more likely to be interpreted as NP-attached. Thus in sentence (3) the PP with a feather is more likely to be given an instrumental interpretation rather than an NP-modifier interpretation; the reverse is true for the $\mathrm{PP}$ with the glasses in sentence (4). Spivey-Knowlton \& Sedivy argue this reflects the selectional restrictions of the verb: an action verb is more likely to appear in a structure with a nominal having an instrument role; a psychological predicate is more likely to appear with an attribute nominal. Recently both Snedeker \& Trueswell (2004) and Kidd \& Cameron-Faulkner (to appear) have reported that children's input and their productions follow this same pattern.

(3) The girl tickled a/the boy with the feather.

(4) The man saw a/the lady with the glasses.

Following from Referential Theory (Crain \& Steedman, I985; Altmann \& Steedman, I988), ambiguous sentences with a definite object NP that are presented without a supporting discourse context are predicted to have VPattachment interpretations more often than sentences with an indefinite 
object NP, regardless of the verb. This follows from the PRINCIPLE of PARSIMONy (Crain \& Steedman, I985), which states that the parser pursues the analysis that requires the fewest referential presuppositions to be fulfilled. This is predicted to be the VP-attachment analysis, since an NPmodifier interpretation requires the postulation of a set of referents over which the modifier identifies a unique entity. Spivey-Knowlton \& Sedivy's ( 1995 ) data supported this prediction. If a supporting context is provided (i.e. a context from which a definite object NP can identify a unique referent from a set), the complex NP modifier interpretation is not predicted to be more difficult, via the PRINCIPLE OF REFERENTIAL SUPPORT (Altmann \& Steedman, I988). When the test sentence in their study contained an indefinite object NP, Spivey-Knowlton \& Sedivy observed a bias for NP-attachment, although the bias was stronger when sentences contained psychological predicates and verbs of perception. Since indefinites do not identify a unique entity from a set, an NP-modifier analysis does not require a restrictive interpretation, and so does not carry additional presuppositional complexity. Thus Spivey-Knowlton \& Sedivy showed the definiteness of the object NP to affect PP-attachment preferences, and their results were broadly consistent with the predictions made by Referential Theory. An alternative explanation for the definiteness effect that does not draw from Referential Theory is distributionally-based: Spivey-Knowlton \& Sedivy showed in a corpus analysis that the predictions made by Referential Theory are also followed in naturally occurring text. In fact, the results of the corpus study better predicted their reading time data, since definiteness interacted with the lexical bias of the verb. On the basis of their results, Spivey-Knowlton \& Sedivy argue for a constraint-based approach to ambiguity resolution: lexical and referential constraints aid comprehension, with verb bias being a strong constraint on comprehension and the definiteness of the object NP a weak constraint.

Trueswell and colleagues have investigated children's resolution of garden-path sentences containing temporary ambiguity of PP-attachment. Using the eye-tracking technique, Trueswell, Sekerina, Hill \& Logrip ( I 999) presented five-year-old children with sentences such as those in (5a) and $(5 \mathrm{~b})$ :

(5a) Put the frog on the napkin in the box.

(5b) Put the frog that's on the napkin in the box.

Both (5a) and (5b) have the same interpretation; however, the PP on the napkin in ( $5 \mathrm{a})$ is potentially ambiguous between an incorrect destination interpretation (on the napkin) and a correct reduced relative interpretation (the frog that's on the napkin), disambiguated only by the PP in the box. Each sentence was presented in the context of an act-out task, and children's eye-movements were recorded as they heard the sentences. There were two 
experimental conditions: a I-referent condition, with only one frog in the experimental scene, and a 2 -referent condition, with two frogs, thus providing the appropriate felicity conditions to process the PP on the napkin as a modifier. Results showed the children preferred the incorrect destination interpretation for sentences like (5a), regardless of whether there were one or two tokens of the head referent. In contrast, adults tested on the same task used the referential information in the 2-referent condition to avoid being garden-pathed. That is, unlike the adults the five-year-old children could not assimilate the referential information (i.e. a definite object NP and a set of referents from which the definite article can identify a unique entity) available to them into their parse of the sentence. Two further experiments by Hurewitz, Brown-Schmidt, Thorpe, Gleitman \& Trueswell (2000) found five-year-old children's preference for a destination interpretation persisted despite attempts to improve the referential saliency of the potential noun modifier interpretation.

In another study, Snedeker \& Trueswell (2004) investigated whether three types of verb bias (instrument bias, modifier bias, no bias), as determined by a norming study conducted with adults, influenced children's immediate attachment decisions when processing globally ambiguous sentences like (6)-(8). The results showed that children only relied on the lexical cue (verb bias); their interpretations, once again, did not differ according to the number of tokens of the head referent available (e.g. whether there were one or two pigs available for (6)). The authors concluded that children form parsing strategies based on their syntactic/semantic knowledge of individual verbs (i.e. a lexical bias), but seemingly not on referential information.

(6) Tickle the pig with the fan (instrument bias)

(7) Feel the frog with the feather (no bias)

(8) Choose the cow with the stick (modifier bias)

The findings of Trueswell et al. (1999), Hurewitz et al. (2000), and Snedeker \& Trueswell (2004) show that while five-year-old children rely on lexical biases in resolving potential ambiguity, they are insensitive to referential information. That children use lexical cues to aid ambiguity resolution suggests that they are attuned very early to the complex relationship between a verb's meaning, its argument structure, and the frequency with which it occurs in different syntactic environments. This is consistent with other psycholinguistic research investigating the processing of structural ambiguity by adults (e.g. Spivey-Knowlton \& Sedivy, I995; Hare, McRae \& Elman, 2003), and with work conducted on the acquisition of verb argument structure (Naigles, I 990; Fisher, Gleitman \& Gleitman, I991; Fisher, I996). Five-year-old children's inability to use referential information can potentially be explained by Karmiloff-Smith's ( I 979, I 985 , I986) three-phase model of development, which argues that children must 
have considerable experience with language, passing through three phases, before they can integrate linguistic and extralinguistic information. In particular, her work on the acquisition of the determiner system suggests that children do not use the definite article in a discourse-appropriate manner until well into their school-age years. The research reported below investigated the types of lexical and referential cues three-nine-year-old children are sensitive to in their interpretations of sentences containing ambiguity of PP-attachment.

\section{STUDY I}

In Study I, children aged five-, seven-, and nine-years were tested using an off-line picture-pointing task with V-NP-PP sentences like (I). There was manipulation of verb semantics, definiteness of the object noun phrase, and type of preposition (with versus locative on). Based on the empirical findings of Trueswell et al. (I999) and Snedeker \& Trueswell (2004), it was predicted that the youngest children would rely solely on verb semantics as a cue to resolving attachment ambiguity. Since we provided children with a felicitous context for a complex NP interpretation we predicted the older children would choose this interpretation when hearing a definite article with an object NP; this prediction derives from Karmiloff-Smith's ( I 985 , I 986) work on the acquisition of the functional properties of the determiner system.

Type of preposition has not been tested explicitly in studies on children's sentence comprehension, although researchers have argued that the preposition type affects attachment preference (e.g. Hindle \& Rooth, I993; MacDonald, Pearlmutter \& Seidenberg, I994). This manipulation was included because we were interested in children's interpretation with different prepositions. Given the polysemous nature of with (Kidd \& Cameron-Faulkner, to appear) and on (Rice, 2003), it was assumed that children might not have acquired the full range of uses of these prepositions by age 5;0 and thus there would be some developmental changes in interpretation over the age range tested. We hypothesized there would be fewer NP-attachments for with than for on since with encodes an instrument phrase which is likely to be associated with the verb.

\section{METHOD}

\section{Participants}

Ninety children were recruited from a registry of volunteer families held in the School of Psychological Science at La Trobe University, and from primary schools throughout the Melbourne metropolitan area. The sample consisted of three age groups: five-, seven-, and nine-year-olds. There were 
34 children aged between $4 ; 7$ and 5 ; Io (mean age: 5; I), 29 aged between $6 ; 6$ and 7; ro (mean age: 7; I), and 27 children ages between $8 ; 4$ and 9;8 (mean age: 9; 1 ). Gender was fairly evenly distributed in each age group. The children all came from English-speaking homes, and had no known language impairment. Two children were excluded from the final analyses because of a clear side bias, choosing the picture on one side (right or left) for more than $80 \%$ of choices.

\section{Design}

The study had a (3) age: five-, seven-, nine-year-old $\times(2)$ verb semantics: activity verbs and verbs of perception $\times(2)$ definiteness of object $\mathrm{NP} \times(2)$ preposition: with and on mixed design. Age and the definiteness of the object NP were between-subjects variables, and verb semantics and preposition type were within-subjects variables.

\section{Materials}

A requirement was that the test sentences could be represented in pictures, and could be understood by children as young as 5 ; o. To select the stimulus material, a pilot study was conducted in which 20 adult participants were asked to paraphrase a set of 22 potentially ambiguous V-NP-PP sentences. From their responses I I sentences were chosen: two practice items and nine experimental items. All I I sentences produced paraphrases of both possible interpretations, NP- and VP-attachment. That is, the sentences were ambiguous for adults. Three of the items contained an activity verb and the preposition with, three contained verbs of perception and the preposition with, and three contained activity verbs and the locative preposition on (see Appendix A). For each item two pictures were drawn by an artist, one corresponding to the VP-attachment interpretation, and one to the NP-attachment interpretation (see Figure I for two examples).

The VP-attachment picture always showed an instrumental interpretation of the PP. For example, for the sentence 'The woman waved to a/the man with the flag', in Figure $\mathrm{I}$, the picture shows the girl using a flag. For the sentence 'The spy saw a/the policeman with the binoculars', the picture shows the spy using the binoculars. The NP-attachment picture showed the complex noun modifier interpretation. For example, in Figure I, the picture for the sentence 'The woman waved to a/the man with the flag' illustrates a man holding the flag, with another man in the scene. Similarly, the picture for the sentence 'The spy saw a/the policeman with the binoculars' shows a policeman holding binoculars, and another policeman partially occluded in the scene. Thus the NP-attachment picture provided the conditions to support a complex noun modifier interpretation: there were two tokens of 

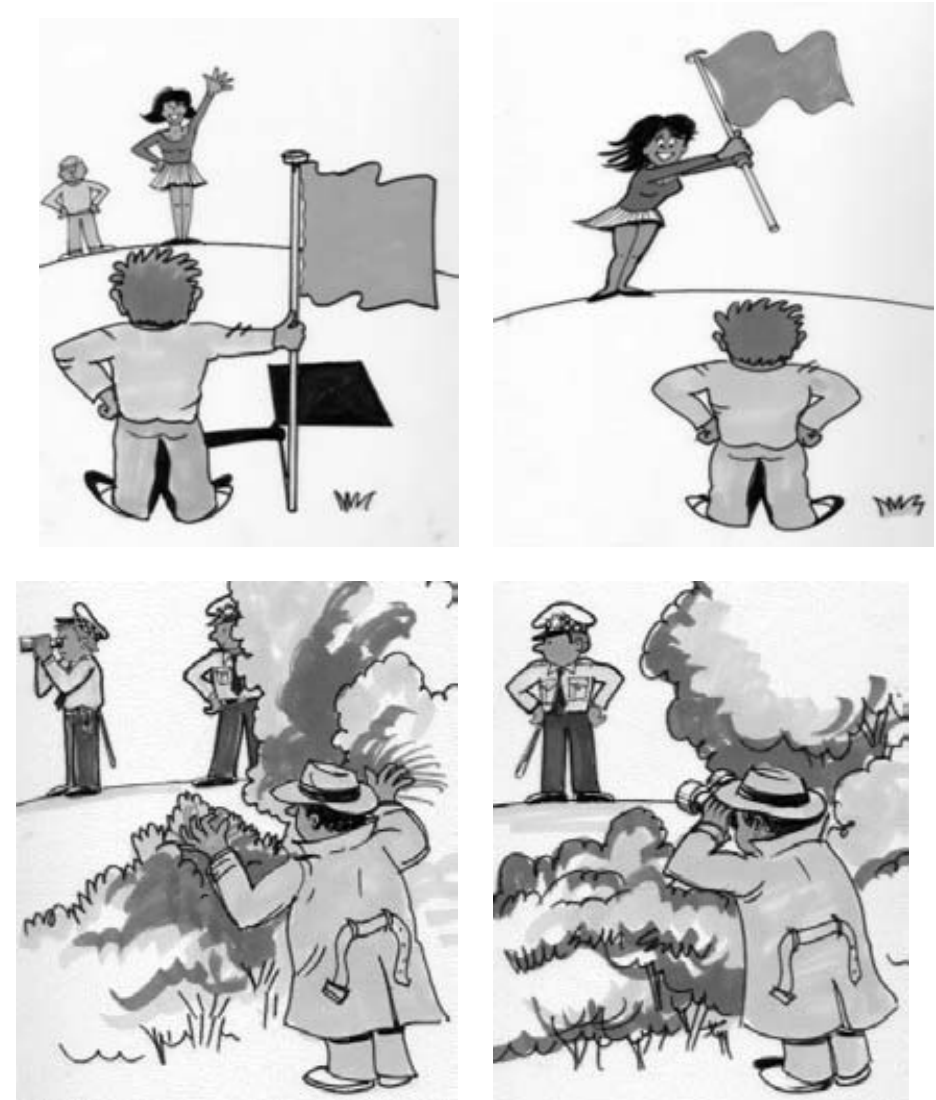

Fig. I. Experimental pictures for the test sentences 'The woman waved to a/the man with the flag' and 'The spy saw a/the policeman with the binoculars'.

the noun (man and policeman). The pictures for each pair were laminated separately and put into a two-ring binder with each picture on a separate page and with two pictures for each set facing each other, as in a book.

\section{Procedure}

Children were tested individually, either in the Language Laboratory in the School of Psychological Science at La Trobe University, or in a quiet area in the child's school. Informed consent was obtained from all children's parents/guardians. The children were told they would be shown two pictures, and that the experimenter would say a description of one of the pictures. The children were told to point to the picture they thought the experimenter was describing. No child had problems understanding this 


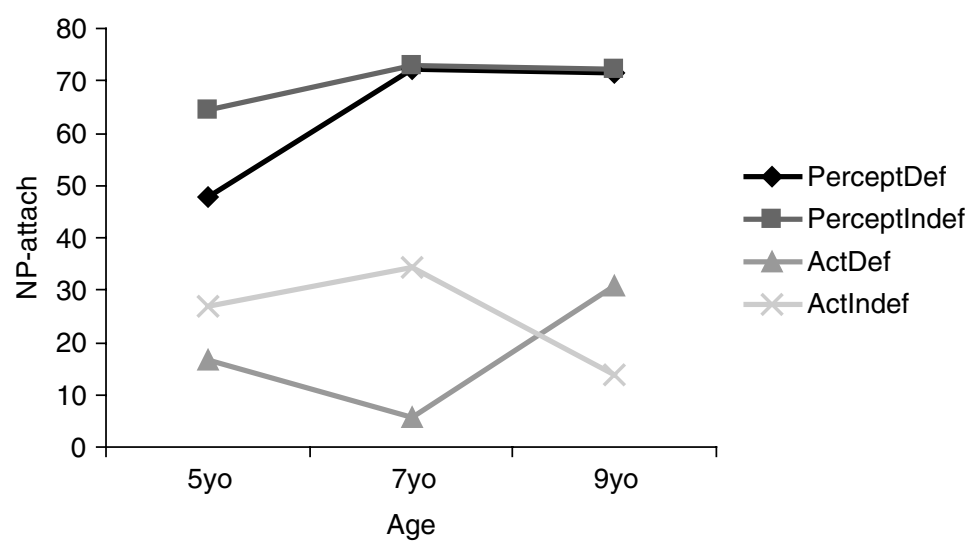

Fig. 2. Percentage of NP-attachment as a function of age and determiner by verb class.

instruction. All readily chose one of the pictures. ${ }^{1}$ Two practice items were used to familiarize children with the experimental procedure. Testing lasted approximately i 5-20 minutes.

The order of presentation of test sentences was counterbalanced. Four orders were used; children were randomly assigned to one order. Because noun-definiteness was a between-subjects variable, half the children heard the test sentences with a definite object NP, and the other half heard the test sentences with an indefinite object NP.

\section{RESULTS}

The percentages of NP-attachments were calculated for each age group. Those for the sentences containing with (activity and perception verbs) are shown in Figure 2.

Figure 2 shows that ambiguous PPs in sentences containing verbs of perception were more likely to be NP-attached than sentences containing activity verbs. Ambiguous PPs were more likely to be NP-attached when the test sentence contained an indefinite object NP than when the object NP was definite. This was true for five-year-olds for sentences containing activity verbs and for sentences containing verbs of perception, and true for seven-year-olds for activity verbs. Nine-year-old children responded differently. For sentences containing activity verbs, nine-year-olds made more NP-attach interpretations when the object NP was definite than when the object NP was indefinite.

[I] Only one nine-year-old girl suggested that both pictures could be illustrative of the test sentence. This occurred on only one trial in her test session, and only after she had made an initial choice. For this trial her initial choice was taken as her picture preference. 
Since percentage data are inherently positively skewed, the raw percentage data were transformed using a $\log _{10}(x+\mathrm{I})$ transformation. A preliminary analysis that included gender as an independent variable yielded no significant effects, and thus the data were collapsed across gender. To test whether verb type and determiner type influenced attachment choices, a (3) age $\times(2)$ verb $\times(2)$ determiner type mixed ANOVA was performed on these data. A significant main effect for verb type suggested that children were more likely to make an NP-attachment when the test sentence contained a verb of perception $(F(\mathrm{I}, 78)=\mathrm{I02} .0 \mathrm{I}, \quad p<0.00 \mathrm{I}$, partial $\left.\eta^{2}=0.567\right)$. An age $\times$ determiner interaction was significant, suggesting that the different age groups did not use the referential information of the determiner in the same manner $\left(F(2,78)=5.94, p=0.004\right.$, partial $\left.\eta^{2}=0.132\right)$. This effect was subsumed by a significant three-way verb $\times$ age $\times$ determiner interaction $\left(F(2,78)=5.887, p=0.004\right.$, partial $\left.\eta^{2}=0.13 \mathrm{I}\right)$.

The three-way interaction suggests that the age $\times$ determiner interaction was carried by children's performance on one type of verb, and so separate univariate ANOVAs were conducted using NP-attachment preference for each verb type as the dependent variable. For the verbs of perception the ANOVA yielded a significant main effect for age, indicating the age groups responded differently $\left(F(2,78)=4.133, p=0.02\right.$, partial $\left.\eta^{2}=0.095\right)$. LEAST SIGNIFICANT DIFFERENCE (LSD) pairwise comparisons of the group means showed that the five-year-old children made significantly less NPattachment interpretations than both the seven-year-olds $(p=0.02)$ and the nine-year-olds $(p=0.025)$.

For the activity verbs the ANOVA yielded a significant age $\times$ determiner interaction $\left(F(2,78)=6.6\right.$ I $_{5}, p=0.002$, partial $\left.\eta^{2}=0 . \mathrm{I}_{45}\right)$. To interpret this interaction a simple main effects analysis compared differences in responding between age groups tested on the same determiner type, and compared differences within each age group between groups tested on different determiner types. The results showed that seven-year-old children made significantly more NP-attachments when the object NP was indefinite $(p=0.003)$. Conversely, nine-year-old children made significantly more NP-attachments when the object NP was definite $(p=0.046)$. Nine-year-old children made more NP-attachments than seven-year-old children when the object NP was definite $(p=0 \cdot 0 \circ \mathrm{I})$. The difference between the means of the nine-year-old and seven-year-old children tested with an indefinite object NP approached significance in the opposite direction $(p=0.069)$. No other simple main effects were significant.

The percentage of NP-attachments for the test sentences with activity verbs containing the preposition on compared with the results of the sentences containing activity verbs and the preposition with are shown in Figure 3 (Recall, no verbs of perception were used with on). 


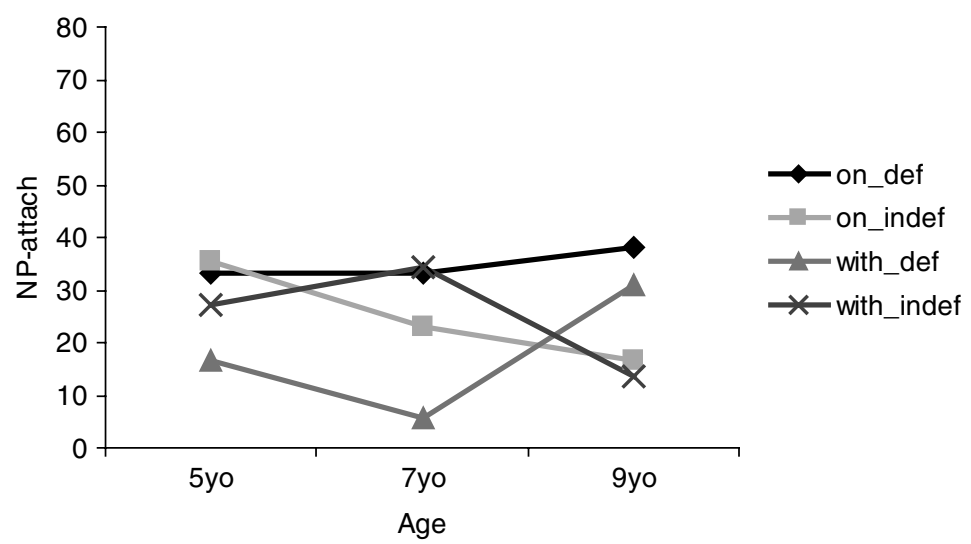

Fig. 3. Percentage of NP-attachments as a function of age and determiner by preposition type.

Figure 3 shows that sentences with the locative preposition on were more often interpreted as NP-attached than sentences with the preposition with, although both prepositions yielded a large percentage of VP-attachments.

A preliminary analysis that included gender as an independent variable yielded no significant effects, and thus the data were collapsed across gender. A (3) age $\times(2)$ preposition $\times(2)$ determiner type mixed ANOVA was performed. A significant main effect for preposition type suggested that sentences with the preposition on resulted in significantly more NPattachments than sentences containing the preposition with $(F(\mathrm{I}, 78)=$ $7 \cdot 569, p=0.007$, partial $\left.\eta^{2}=0.09\right)$. A significant age $\times$ determiner interaction was also observed $\left(F(2,78)=4.183, p=0.019\right.$, partial $\left.\eta^{2}=0.097\right)$. This interaction was largely carried by the results from the sentences containing the preposition with, as Tukey/Kramer post hoc comparisons collapsing for preposition type showed no significant differences. This was further confirmed by a simple main effects analysis using the responses to sentences containing on, which yielded only one significant result: a difference between the indefinite and definite groups for the nine-year-old children $(p=0 \cdot 044)$. The three-way preposition $\times$ age $\times$ determiner interaction also indicated a trend $\left(F(2,78)=2 \cdot 775, p=0.068\right.$, partial $\left.\eta^{2}=0.066\right)$.

\section{DISCUSSION}

The prediction that children would be influenced by verb type was supported by the results of the study. Attachment preferences differed according to verb type in all age groups. Only the nine-year-old children appeared to understand the uniqueness function of the definite article, as 
evidenced by their performance on sentences containing activity verbs. Note that this effect was not observed for verbs of perception, where the strong bias of verb semantics predicts NP-attachment.

The results from the analysis of preposition type supported the hypothesis that there would be more VP-attachment interpretations when test sentences contained the preposition with than when they contained the locative preposition on. Overall, however, PPs headed by on were VP-attached. As all sentences containing on had activity verbs this suggests the location of an activity is important to children. However, the results show some interactions with definiteness. Five- and seven-year-old children appeared to make no distinction between the determiners when tested with on ; nine-yearolds made more NP-attachments when the determiner was definite, showing their awareness of the uniqueness function of the definite article. The nine-year-olds tested with the definite objects also differed from the other age groups when tested on sentences containing with. Thus we have evidence for sensitivity to a bias for preposition type, and for the nine-yearolds, there is also sensitivity to definiteness. The findings concerning the effect of verb on sentence comprehension by five-year-olds are consistent with those from previous research reported in the literature (Trueswell et al., I999; Snedeker \& Trueswell, 2004). Sensitivity to the functional properties of definiteness has been shown to develop between 7;0 and 9;0 (Karmiloff-Smith, I985, I986); the role of prepositions has not previously been reported. We discuss these findings further in the General Discussion.

\section{STUDY 2}

The results from Study I suggest that children are not sensitive to the uniqueness function of the definite article in the object NP, and do not match this to the referential scene, until around 9; 0 . The referential manipulation in Study I was rather subtle: children were required to notice the existence of a set of potentially modifiable referents in one of the pictures. Study 2 investigated the possibility that young children are capable of overriding their lexical preference for an instrumental interpretation in favour of a NP-modifier interpretation.

Children were presented with V-NP-PP sentences such as Chop the tree with the leaves, where there was conflict between the cue of verb semantics (action verbs that bias instrumental interpretation) and the content of the PP. For the sentence Chop the tree with the leaves, children were presented with two trees, one with leaves and one without leaves, an axe, and a set of leaves that could be used as an instrument. The children were required to act out the test sentence using the toy props. If children identified the mismatch between the bias of verb semantics (chop requires an instrument) and the content of the PP (leaves are a bad instrument), then it was 
hypothesized that they would search other aspects of the scene to interpret the sentence. The presence of an axe, an instrument used for chopping, could lead children to apply a NP-modifier interpretation to the $\mathrm{PP}$, thus inducing referential processing.

Furthermore, Study 2 investigated whether three-year-old children also use lexical biases to resolve PP-attachment ambiguity. In addition to the sentences that contained conflicting thematic fit between the verb and PP, children were tested on sentences that contained verbs that biased an instrumental interpretation and verbs that biased a modifier interpretation. Investigating whether these effects are present at younger ages is important, since the younger a verb by attachment effect is observed, the stronger the claim that children acquire these parsing preferences as a result of lexical learning becomes. It was hypothesized that verb bias would influence both three- and five-year-old children's attachment decisions, with instrument bias verbs resulting in more instrument interpretations, and modifier bias verbs resulting in more modifier interpretations.

\section{Participants}

Forty-seven children were recruited from a registry of names at the Max Planck Child Study Centre at the University of Manchester and a primary school in the Greater Manchester Metropolitan Area. Two three-year-olds and one five-year-old were excluded from the final analyses because of restlessness. The final sample consisted of $2 \mathrm{I}$ three-year-olds (mean age: $3 ; 8$, range $3 ; 5-4 ; 0$ ) and 23 five-year-olds (mean age: $5 ; 8$, range $5 ; 4-6 ; \mathrm{I}$ ). No child had any known language impairment or learning difficulty.

\section{Materials}

A set of toys was used corresponding to the NPs in the test sentences. Some additional toys served as distracter instruments. There were two practice sentences and $\mathrm{I} 2$ test sentences. There were three verb bias groups: instrument bias (INS), conflict (CON), and modifier bias (MOD). There were four sentences in each group (see Appendix B). In the INS bias condition, two of the sentences were the same as in Study I. The other two came from Snedeker \& Trueswell (2004), as did the MOD bias sentences. The CON bias sentences were constructed according to the following criteria. First, the verb had to be an action verb and potentially have an implicit instrument; the verbs chop, wipe, poke, and smash were chosen. Second, the NP within the PP had to have a bad (but possible) thematic fit with the verb, such that an instrumental interpretation was unusual. The NP within the PP actually referred to an aspect of the referential scene; for instance, for the sentence Chop the tree with the leaves there were two trees, 
one with leaves and the other without leaves. There was also a toy axe and a set of leaves present. The former would be the correct instrument to use if a NP-modifier interpretation was applied to the PP; the latter used if an instrumental interpretation was applied.

To ensure that the verbs used in the INS and CON sentences were biased towards an instrumental interpretation of with and that the verbs in the MOD sentences were biased to a modifier interpretation, a written sentence completion study was conducted with 25 undergraduates from the University of Manchester. The results confirmed these biases: CON verbs resulted in completions that identified an instrumental role for with $9 \mathrm{r} \%$ of the time, INS verbs resulted in completions that identified an instrumental role for with $79 \%$ of the time, and MOD verbs resulted in completions that identified an instrumental role for with i $6 \%$ of the time (versus $39 \%$ modifier interpretations). ${ }^{2}$

\section{Procedure}

Children were tested using the act-out methodology. The children were told that they were going to play some games with toys. Children sat next to the experimenter, who placed the toys for each test sentence on the table. The children were asked to name the toys before each sentence; the experimenter named any items the children named incorrectly or did not know. When the toys were placed on the table the experimenter asked the child to act out the test sentence, using the request 'Can you ...'. Two practice items introduced the children to the task. The experimenter then moved on to the test sentences. Verb bias was a within-subjects variable. The order of presentation of sentences was psuedorandomized; four orders were used. Testing lasted approximately i 5-20 minutes.

\section{RESULTS}

Children's responses were coded according to their interpretation of the PP: instrumental, modifier, or other. For instance, for the sentence Chop the tree with the leaves, a response where a child used the leaves to chop one of the trees was coded as an instrumental response. ${ }^{3}$ A response where a child used

[2] The rest of the completions for the MOD verbs encoded the manner sense of with (e.g. The little boy looked at the duck with excitement). This is a rather adult usage that children rarely use (see Kidd \& Cameron-Faulkner, to appear).

[3] This included situations where children chopped the tree that had leaves using the free leaves as an instrument; that is, times where children 'chopped the tree that had leaves with the leaves'. Overall, children's choice between the competing tokens was roughly equal. They chose the potentially modifiable referent (e.g. the thee with leaves) $4 \mathrm{I} \%$ of the time when making an instrumental response, and there were no age differences $(t(32)=0.76 \mathrm{I}, p>0.2)$. This suggests that they were choosing the object NP referent at random, and were not processing the PP as a noun modifier. 




Fig. 4. Percentage of instrument responses by verb bias condition and age group.

the axe to chop the tree that had leaves was coded as a modifier response. A response where the child used the axe to chop the wrong tree was coded as an 'other' response. The percentage of INS responses and standard errors for each condition and age group are shown in Figure 4.

The three-year-old group produced more INS responses than the five-year-olds in each verb bias condition. The magnitude of this difference was larger in the CON and MOD conditions than the INS condition. There was a uniform pattern of responding within each age group. The INS bias condition produced the most INS responses, followed by the CON condition and the MOD condition, respectively.

The raw percentage data were transformed using a $\log _{10}(x+\mathrm{I})$ transformation. A preliminary analysis that included gender as an independent variable yielded no significant effects, and thus the data were collapsed across gender. A (3) bias $\times(2)$ age mixed ANOVA was conducted. There was a significant main effect for verb bias $(F(2,4 \mathrm{I})=25.737, p<0.00 \mathrm{I}$, partial $\left.\eta^{2}=0.557\right)$, suggesting that the children in both age groups responded differently across bias conditions. There was a significant main effect for age $\left(F(\mathrm{I}, 42)=\mathrm{I} 2 \cdot 438, p=0.00 \mathrm{I}\right.$, partial $\left.\eta^{2}=0.228\right)$. There was also a significant bias by age interaction $\left(F(2,4 \mathrm{I})=4 \cdot \mathrm{I} 34, p=0.023\right.$, partial $\left.\eta^{2}=0 \cdot \mathrm{I} 68\right)$.

Post hoc Tukey pairwise comparisons showed that both the three- and five-year-old children made significantly more instrumental responses in the INS bias condition than in the CON and MOD bias conditions (all $p$ 's $<0.05$ ), but did not differ statistically in their responses in CON and MOD bias conditions. Tukey/Kramer post hoc comparisons showed that the three-year-old children made significantly more instrumental responses than the five-year-old children in the $\mathrm{CON}(p<0.05)$ and MOD bias conditions $(p<0.0 \mathrm{I})$, but not in the INS bias condition $(p>0.05)$. 
D ISCUSSION

The main effect for verb bias suggests that both three- and five-year-old children are basing their attachment decisions on the lexical bias of the verb. This extends the previous findings from Study i and Snedeker \& Trueswell (2004) to a younger age group. This supports the notion that children are tuning their parsing preferences in the process of lexical acquisition.

The crucial finding in Study 2 is children's performance in the CON condition. Both the three- and five-year-old children made fewer instrumental responses in this condition than in the INS bias condition, despite that fact that the verbs in the $\mathrm{CON}$ sentences were biased towards an instrumental reading of with. The five-year-old children were more successful than the three-year-old children at overriding the instrumental preference in this condition, making only $27 \%$ instrumental responses to the three-year-old children's $59 \%$. Thus we have strong evidence to suggest that five-year-old children are capable of referential processing, but that three-year-old children rely more on the lexical bias of the verb to resolve the syntactic ambiguity.

Overall, the three-year-old children made more instrumental responses than did the five-year-old children. In fact, even in the MOD bias condition the three-year-olds made instrumental responses just under half the time. Thus it could be argued that the three-year-olds are still learning the lexicosemantic restrictions of the modifier bias verbs. It is possible that when children did not have a clear verb bias they relied on other cues to interpret the sentence. A recent corpus study by Kidd \& Cameron-Faulkner (to appear) presents results that provide a potential explanation for this effect. In a case study of one child followed longitudinally from $2 ; 0-4 ; 0$, they showed that both verb class (semantics) and syntactic frame predicted the sense in which with was used. The instrumental sense most often occurred in V-NP-with-PP frames (as opposed to other frames, e.g. V-with-NP) and with action verbs. It is therefore possible that the three-year-old children in the present study were relying more on the cue of syntactic frame. Support for this suggestion comes from the work of Naigles and colleagues (Naigles, Fowler, \& Helm, I 992), who have shown that young children show greater frame compliance than older children when interpreting known verbs in unattested syntactic frames (e.g. they interpret The zebra comes the giraffe by enacting a transitive action).

An alternative explanation for the difference between the three- and five-year-old children is that the children were following the general parsing heuristic MA (Frazier, 1987), and that the three-year-olds were less capable of revising an initial structural parse using non-syntactic information than were the five-year-old children. Our data do not speak to this issue, since our studies were conducted off-line. However, the weight of evidence using on-line methodologies suggests that children do not follow MA. Snedeker \& 
Trueswell (2004) found no evidence for MA in their eye-tracking study, and in a recent study testing eight-year-old children using the self-paced listening technique, Kidd \& Bavin (2005) found no overwhelming evidence for MA either. Of course, this leaves open the possibility that children do rely on a structural parsing heuristic such as MA when they are younger than five-years. This is an empirical question that awaits further research.

\section{GENERAL DISCUSSION}

The results of the two studies reported support earlier findings that young children use lexico-semantic cues to resolve structural ambiguity. Children of all ages in both studies were sensitive to the manipulation of verb semantics. This suggests that at least by around age $3 ; 6$ children are sensitive to the distributional properties of verbs. Both Snedeker \& Trueswell (2004) and Kidd \& Cameron-Faulkner (to appear) have shown in analyses of naturalistic corpora that these cues are probabilistically available in the input. When similarities in distribution are perceived, verbs that behave similarly can be linked. This is consistent with the general proposals made by Bates \& MacWhinney (I989) and Seidenberg \& MacDonald (I999), and supported by the distributional approach to children's early language development (Fisher et al., г991; Fisher, I996; Lieven, Pine \& Baldwin, I 997; Tomasello, 2003).

The results from the present research suggest that children do not consistently incorporate referential cues to interpretation until at least age $5 ; \circ$, and that more subtle discourse-based cues such as definiteness are not used until around age 9; 0 . We first consider children's use of definiteness as a cue to interpretation, and then consider the referential effects found in Study 2 .

The five- and seven-year-old children in Study I were not sensitive to the referential function of definiteness. That is, they did not construe the definite object NP as referring to a unique entity from a set (i.e. the $\mathrm{NP}$-attachment picture). This is consistent with findings from previous studies by Trueswell et al. (I 999), Hurewitz et al. (2000), and Snedeker \& Trueswell (2004), who found that five-year-old children were unable to exploit pragmatic/referential information to resolve PP-attachment ambiguity. Instead, both the five- and seven-year-old children made more $\mathrm{VP}$-attachment interpretations of the sentences that contained activity verbs with a definite object NP than those that contained an indefinite object NP. The difference was significant for the seven-year-old children only. This result suggests that these children were not incorporating aspects of the referential scene into their interpretation of the sentence. That is, they could be argued to be following something like Crain \& Steedman's ( 1985 ) PRINCIPLE OF PARSIMONy. Alternatively, it is possible that, following 
Spivey-Knowlton \& Sedivy (I995), the children were basing their interpretations on distributional information. ${ }^{4}$ The pattern of results for these children is predicted by the distributional account: definite object NPs bias VP-attachment when sentences contain activity verbs; the bias for indefinites is equally weighted (see Spivey-Knowlton \& Sedivy, I 995). This explanation suggests that object NP definiteness can exert an effect on interpretation without recourse to the referential scene.

The gradual development of sensitivity to the referential constraint of definiteness is consistent with Karmiloff-Smith's (1979, I985) work on the acquisition of the determiner system. Karmiloff-Smith outlined a model of representational change that describes the development of children's ability to integrate language and the world. In the first phase of the model, children's use of the definite determiner is deictic; it is not used to identify uniqueness as in the adult system. No representational link is made between the definite and indefinite determiner, although they may be used for different functions. In phase 2 there is top-down processing. That is, children are aware of the different discourse functions of determiners and apply these rigidly to interpretation, often without regard to extralinguistic factors such as the referential context. Such a pattern seemed to be followed by the seven-year-old in Study I. For the activity verbs, the seven-year-olds treated the definite article as identifying a unique entity in the VP-attachment picture, thereby suggesting that they chose the picture where, for instance, there was one man in the picture rather than two (for The woman waved to the man with the flag), and not treating the definite article as identifying a unique entity from a set. For the verbs of perception, however, there was no difference between the definite and indefinite determiner conditions since in this condition the cues were not in conflict; the cue of verb semantics predicts NP-attachment. By phase 3 in Karmiloff-Smith's model children are able to integrate different sources of knowledge in a flexible manner. The results of the Study I suggest that the nine-year-old children could assimilate the uniqueness function of the definite determiner into their parse of the sentence, and consequently match the picture depicting the complex noun-modifier interpretation.

The results of Study 2 showed that when the semantics of the verb and its potential instrument have bad thematic fit, five-year-olds (and to a lesser extent, three-year-olds) are able to override their preference for an instrumental interpretation in favour of a noun modifier interpretation. This suggests that young children are not wholly insensitive to referential cues to interpretation. This appears to be a feature of the language processing system that takes some time to develop, since the three-year-old children largely preferred to base their interpretation on the lexical bias of the verb. One

[4] We thank an anonymous reviewer for suggesting this interpretation.

\section{2}


potential explanation for the difference between the three- and five-year-old children in the CON condition in Study 2 derives from research on the development of inhibition in young children. To provide a noun modifier response in the $\mathrm{CON}$ bias condition children had to inhibit a dominant response, an instrumental interpretation of the $\mathrm{PP}$, in favour of a seemingly less preferred alternative. Research conducted by Zelazo and colleagues (e.g. Zelazo, Frye \& Rapus, I 996) show consistent differences between three- and five-year-old children in their ability to inhibit dominant responses and shift attention. While the role of attentional processes and executive control has not been studied extensively in normal language acquisition, they have been shown to play a role in the development of metalinguistic awareness (Bialystok, I999). The extent to which executive processes contribute to ambiguity resolution appears to be a fruitful avenue of future research.

The current paper has reported on two studies investigating the sources of information used by children in resolving structurally ambiguous sentences. However, as noted earlier, we have reported off-line data, and so our data can only identify the sources of information children ultimately use in their final interpretation of a sentence. We take our results to be consistent with probabilistic 'constraint-satisfaction' models of adult sentence processing (e.g. MacDonald et al., I 994). These models belong to the same class as the Competition Model (Bates \& MacWhinney, r 989). According to these models parsing preferences are forged over time: lexical cooccurrence statistics are registered by the parser, which uses these statistics to process incoming language. Those cues that are most reliably attested in the input are more likely to drive interpretation over cues that are less reliable. Our findings cannot rule out structurally-driven approaches to parsing, which do not admit a determining role for input in the forging of parsing preferences (e.g. Crain \& Thornton, I998; Fodor, I998; Frazier, I987). However, the research reported provides a basis from which similar questions can be asked using on-line methodologies. Such research should lead to a clearer understanding of children's processing mechanisms.

\section{REFERENCES}

Altmann, G. \& Steedman, M. (I988). Interaction with context during human sentence processing. Cognition 30, I $9 \mathrm{I}-238$.

Bates, E. \& MacWhinney, B. (I989). Functionalism and the competition model. In B. MacWhinney \& E. Bates (eds), The crosslinguistic study of sentence processing. Cambridge: CUP.

Bever, T. G. (I970). The cognitive basis for linguistic structures. In J. R. Hayes (ed.), Cognition and the development of language. New York: John Wiley \& Sons.

Bialystok, E. (1999). Cognitive complexity and attentional control control in the bilingual mind. Child Development 7o, $636-44$.

Booth, J. R., MacWhinney, B. \& Harasaki, Y. (2000). Developmental differences in visual and auditory processing of complex sentences. Child Development 74, 981-1003. 
Clifton, C. \& Ferreira, F. (1989). Ambiguity in context. Language and Cognitive Processes 4 , 77-IO3.

Crain, S. \& Steedman, M. (1985). On being led up the garden path: the use of context by the psychological syntax processor. In L. K. D. Dowty \& A. Zwickey (eds), Natural language parsing. Cambridge: CUP.

Crain, S. \& Thornton, R. (1998). Investigations in Universal Grammar. Cambridge, MA: MIT Press.

Ferreira, F. \& Clifton, C. (1986). The independence of syntactic processing. Fournal of Memory \& Language 25, 348-68.

Fisher, C. (1996). Structural limits on verb mapping: the role of analogy in children's interpretations of sentences. Cognitive Psychology 3I, 4I-8I.

Fisher, C., Gleitman, H. \& Gleitman, L. (I99I). On the semantic content of subcategorisation frames. Cognitive Psychology 14, 33 I-92.

Fodor, J. D. (1998). Parsing to learn. Fournal of Psycholinguistic Research 27, 339-74.

Frazier, L. (1987). Sentence processing: a tutorial review. In M. Coltheart (ed.), Attention and performance XII : the psychology of reading. Hillsdale, NJ : Erlbaum.

Frazier, L. \& de Villiers, J. (eds) (1990). Language processing and language acquisition. Dordrecht: Kluwer.

Hare, M., McRae, K. \& Elman, J. (2003). Sense and structure: meaning as a determinant of verb subcategorization preferences. Fournal of Memory and Language $\mathbf{4 8}$, $28 \mathrm{I}-303$.

Hindle, D. \& Rooth, M. (I993). Structural ambiguity and lexical relations. Computational Linguistics 19, 103-20.

Hurewitz, F., Brown-Schmidt, S., Thorpe, K., Gleitman, L. \& Trueswell, J. C. (2000). One frog, two frog, red frog, blue frog: factors affecting children's syntactic choices in production and comprehension. Fournal of Psycholinguistic Research 29, 597-626.

Jusczyk, P. W. (1997). The discovery of spoken language. Cambridge, MA: MIT Press

Jusczyk, P. W. (2002). How infants adapt speech-processing capacities to native language structure. Current Directions in Psychological Science II, I 5-I8.

Karmiloff-Smith, A. (I 979). A functional approach to child language. Cambridge: CUP.

Karmiloff-Smith, A. (1985). Language and cognitive processes from a developmental perspective. Language and Cognitive Processes $\mathbf{I}, 6 \mathrm{I}-85$.

Karmiloff-Smith, A. (I986). From meta-process to conscious access: evidence from children's metalinguistic and repair data. Cognition 23, 95-I 47.

Kidd, E. \& Bavin, E. L. (2005). Lexical and referential influences on on-line spoken language comprehension: a comparison of adults and primary-school age children. Unpublished Ms: La Trobe University.

Kidd, E. \& Cameron-Faulkner, T. (to appear). The acquisition of the multiple senses of with. Linguistics.

Lieven, E. V. M., Pine, J. M. \& Baldwin, G. (I997). Lexically-based learning and early grammatical development. Fournal of Child Language 24, I87-2 I9.

MacDonald, M. C., Pearlmutter, N. J. \& Seidenberg, M. S. (I994). Lexical nature of syntactic ambiguity resolution. Psychological Review ror, 676-703.

MacWhinney, B. \& Bates, E. (I989). The crosslinguistic study of sentence processing. Cambridge: CUP

Mintz, T. H., Newport, E. L. \& Bever, T. G. (2002). The distributional structure of grammatical categories in speech to young children. Cognitive Science 26, 393-424.

Naigles, L. (1990). Children use syntax to learn verb meanings. Fournal of Child Language I7, 357-74.

Naigles, L., Fowler, A. \& Helm, A. (I992). Developmental shifts in the constructions of verb meanings. Cognitive Development 7, 403-28.

Rayner, K., Carlson, M. \& Frazier, L. (1983). The interaction of syntax and semantics during sentence processing: eye movements in the analysis of semantically biased sentences. Fournal of Verbal Learning and Verbal Behavior 22, 358-74. 
Rice, S. (2003). Growth of a lexical network: nine English prepositions in acquisition. In H. Cuyckens, R. Dirven \& J. Taylor (eds), Cognitive approaches to lexical semantics. Berlin: Walter De Gruyter.

Seidenberg, M. S. \& MacDonald, M. C. (I999). A probabilistic constraints approach to language acquisition and processing. Cognitive Science 23, 569-88.

Snedeker, J. \& Trueswell, J. C. (2004). The developing constraints on parsing decisions: the role of lexical-biases and referential scenes in child and adult sentence processing. Cognitive Psychology 49, 238-99.

Spivey-Knowlton, M. \& Sedivy, J. (1995). Resolving attachment ambiguities with multiple constraints. Cognition 55, 227-67.

Taraban, R. \& McClelland, J. (I988). Constituent attachment and thematic role expectations. Fournal of Memory and Language 27, 597-32.

Taraban, R. \& McClelland, J. (I990). Sentence comprehension: a multiple constraints view. In D. Balota, K. Rayner \& G. Flores D'Arcais (eds), Comprehension processes in reading. Hillsdale, NJ : Erlbaum.

Tomasello, M. (2003). Constructing a language. Cambridge: Harvard University Press.

Trueswell, J. C., Sekerina, I., Hill, N. M. \& Logrip, M. L. (I999). The kindergartenpath effect: studying on-line sentence processing in young children. Cognition $\mathbf{7 3}$, $89-\mathrm{I} 34$.

Zelazo, P., Frye, D. \& Rapus, T. (1996). Age related dissociation between knowing rules and using them. Cognitive Development II, 37-63.

\section{APPENDIX A}

TEST ITEMS FOR STUDY I

Activity verbs

The woman waved to a/the man with the flag

The girl hit a/the boy with the book

The man touched an/the ostrich with the ribbon

\section{Verbs of perception}

The spy saw a/the policeman with the binoculars

The boy listened to a/the girl with the hearing aid

The lady looked at a/the man with the glasses

\section{Sentences containing locative preposition}

The man chased a/the boy on the bicycle

The girl followed a/the boy on the skateboard

The boy read a/the book on the castle 


\section{APPENDIX B}

TEST SENTENCES FOR STUDY $3 *$

\begin{tabular}{ll}
\hline Bias & Sentence \\
\hline INS & Tickle the hippo with the feather \\
INS & Wave to the man with the flag \\
INS & Hit the boy with the book \\
INS & Knock down the dog with the stick \\
CON & Chop the tree with the leaves \\
CON & Poke the dog with the scarf \\
CON & Wipe the girl with the hat \\
CON & Smash the vase with the flower \\
MOD & Look at the duck with the glasses \\
MOD & Find the dog with the stick \\
MOD & Choose the giraffe with the spoon \\
MOD & Hug the cow with the blanket \\
\hline
\end{tabular}

* INS = instrument bias verbs, $\mathrm{CON}=$ conflict bias verbs, $\mathrm{MOD}=$ modifier bias verbs. 